\title{
Hair Cortisol Concentration Differs Across Site and Person: Localisation and Consistency of Responses to a Brief Pain Stressor
}

\author{
C. F. SHARPLEY ${ }^{1}$, K. G. KAUTER ${ }^{1}$, J. R. MCFARLANE ${ }^{1}$ \\ ${ }^{1}$ Brain-Behaviour Research Group, University of New England, Armidale, Australia
}

Received August 12, 2009

Accepted April 16, 2010

On-line June 9, 2010

\begin{abstract}
Summary
Although in vitro studies have shown that cortisol concentrations in human and animal hair respond to environmental stressors, few data have been reported regarding the in vivo variability of hair cortisol to brief pain stressors. As an extension of a previous study, hair was collected and assayed for cortisol concentrations from each of three sites (elbow, mid-forearm, wrist) before and after participants immersed their hand in ice water for $1 \mathrm{~min}$. Results showed that the "localization" boundary of hair cortisol responses previously reported was able to be reduced to only $250 \mathrm{~mm}$ between sites. Furthermore, all participants showed considerable variability in hair cortisol across the three sites at each collection period, although consistency across participants in overall responsivity of hair cortisol to the pain stressor was observed.
\end{abstract}

\section{Key words}

Cortisol • Hair • Stress $\bullet$ Peripheral HPA axis

\section{Corresponding author}

C. F. Sharpley, PO Box 378, Coolangatta, QId, 4225, Australia. E-mail: csharpley@onthenet.com.au

\section{Introduction}

Cortisol is the principal glucocorticoid in humans and has vital anti-inflammatory and immunosuppressive effects on all tissues including the skin (Weissman and Thomas 1963, Klaitman and Almog 2003). As part of the hypothalamic-pituitary-adrenal axis (HPA), cortisol is produced by the adrenal cortex following ACTH stimulation from the pituitary and is regulated by the hypothalamic peptide $\mathrm{CRH}$ which arises in the hypothalamus (Aron et al. 2007). Although a basal concentration of cortisol is required at all times (Guyton and Hall 2006), various physical or mental stressors can elevate central cortisol concentration (Sharpley and McLean 1992, Dickerson and Kemeny 2004).

Cortisol has traditionally been assayed from serum, urine and saliva in various studies as a measure of physiological response to stress (Umeda et al. 1981) but has recently been shown to be synthesized in skin (Arck et al. 2006) and hair (Yang et al. 1998, Wheeler et al. 1998, Koren et al. 2002, Klein et al. 2004, Raul et al. 2004, Davenport et al. 2006, Sauve et al. 2007, Van Uum et al. 2008, Yamada et al. 2007). The production of cortisol in the hair follicle, as evidenced by its presence along the hair shaft, is particularly interesting because it has been assumed that the hair shaft above skin level is dead (Harkey 1993). However, some studies have challenged this view by showing that sex steroid levels within the whole hair shaft vary in parallel with serum steroid concentrations during the menstrual cycle in women (Yang et al. 1998). These concentrations are not affected by washing of the hair, which has been shown to remove less than $7 \%$ of the total hormone extracted (Cirimele et al. 2000, Raul et al. 2004).

These findings have established the existence of a "peripheral" HPA axis in skin and hair (Slominski et al. 2005, Arck et al. 2006, Paus et al. 2006). That is, as well as being targets for HPA axis activity, skin and hair are also producers of cortisol via their own neuroendocrine systems which include $\mathrm{CRH}$, POMC, ACTH (Aron et al. 2007) and cortisol itself, all of which have been shown to be secreted by human hair follicles (Klein et al. 2004, Ito et al. 2005, Kalra et al. 2005). However, much of the data supporting this model were 
collected from in vitro studies which used expurgated human hair follicles in which the secretion of cortisol in response to ACTH stimulation was delayed by at least $48 \mathrm{~h}$ (Ito et al. 2005). In addition, where hair cortisol concentrations have been shown to be linked to stress, data were gathered from comparison groups (e.g. depressed vs. non-depressed pregnant women) (Kalra et al. 2005) or from a single collection (babies vs. adults) (Klein et al. 2004) over relatively static periods of time. Although valuable in clarifying the presence of hair cortisol concentration differences between stressed and non-stressed individuals, those data do not indicate how quickly hair cortisol concentrations change in response to stressors, nor whether the cortisol response is general or localized to the site of the stressor (e.g. in the case of pain).

Therefore, in a previous paper, we described the timing and the localization of hair cortisol responses to a brief pain stressor by comparison of data collected from hair on the site of pain (a participant's hand which was immersed in ice water) and their opposite lower leg (no immersion or pain) (Sharpley et al. 2009). Hair cortisol concentrations increased dramatically by over $320 \%$ and almost immediately (within one minute) of participants immersing their hands in ice water, much faster than the commonly-reported 18 to $20 \mathrm{~min}$ lag between onset of stress and salivary cortisol concentration increases (Sharpley and McLean 1992). These hair cortisol responses were brief, lasting for less than five minutes after the pain stressor was removed. In addition, while the immersed hand showed increases in hair cortisol concentrations, the opposite (non-immersed) lower leg did not, suggesting that the hair cortisol response was localized. Finally, by reference to salivary cortisol data collected during that experiment, it was clear that the "central" and "peripheral" cortisol responses were independent of each other.

However, the distance between an individual's forearm and lower opposite leg is considerable. While showing that there is localization of hair cortisol response to pain, differences in hair cortisol responses between these two sites do not indicate the degree of localization of those responses. Therefore, in the current study, we gathered hair cortisol data from three sites along the forearms of five men who immersed only the hand of their selected forearm into ice water. These sites are described below, but were within $250 \mathrm{~mm}$ of each other, thus allowing for a more precise test of the degree of localization in hair cortisol responses to a pain stressor.

\section{Methods}

\section{Participants}

Data were collected from five healthy males, (none of whom was taking medication) aged 22, 35, 52, 54 and 61 years. All were volunteers for "a study about how you react to ice water".

\section{Stressor task}

Mild pain was evoked by use of the Cold Pressor Test (CPT). In this procedure, participants immerse their hand in ice water at $1{ }^{\circ} \mathrm{C}$ to $4{ }^{\circ} \mathrm{C}$ for $1.0 \mathrm{~min}$. The CPT has been shown to induce sympathetic responses, including cortisol (Sharpley et al. 2009) but does not cause any injury.

\section{Sample collection and assay}

Hair was collected by shaving samples of about $6 \mathrm{~cm}^{2}$ from three sites on the nondominant forearm of each participant. The first site (wrist) was at the head of the ulna, extending towards the elbow for $45 \mathrm{~mm}$; the third site (elbow) was at the head of the radius, also extending for $45 \mathrm{~mm}$, but towards the wrist; the second site (mid-arm) was centered on the midpoint of the distance between the head of the ulna and the head of the radius, and extended for $22.5 \mathrm{~mm}$ either side of this midpoint. Each of these three sites was bounded by two parallel lines drawn across the forearm and $45 \mathrm{~mm}$ apart and each site was further divided into three equally-sized sub-areas so that each of the three sub-areas was parallel to the arm itself and named $a, d, g$ (wrist), $b, e, h$ (mid-arm) and $c, f, i$ (elbow). These sub-areas were sampled sequentially for each of the three sites as described below.

After shaving, each razor and the hair collected was placed in a labeled paper envelope. After being emptied from the envelopes and placed in separate glass vials $(20 \mathrm{ml})$, hair was weighed and then chopped with scissors (washed with methanol between samples) before being extracted with $3 \mathrm{ml}$ of methanol for $24 \mathrm{~h}$. The methanol was then decanted into polypropylene tubes $(3.5 \mathrm{ml})$ and evaporated under vacuum. Gel buffer (100 $\mu \mathrm{l}$ ) (phosphate buffer $0.05 \mathrm{M}$, saline $0.15 \mathrm{M}$, pH 7.5 containing $0.1 \%$ gelatin) were added and allowed to stand at room temperature for $60 \mathrm{~min}$ prior to assay. Cortisol concentrations were determined by radioimmunoassay as previously described (Yuen et al. 2004).

\section{Procedure}

Each participant was treated separately. After 

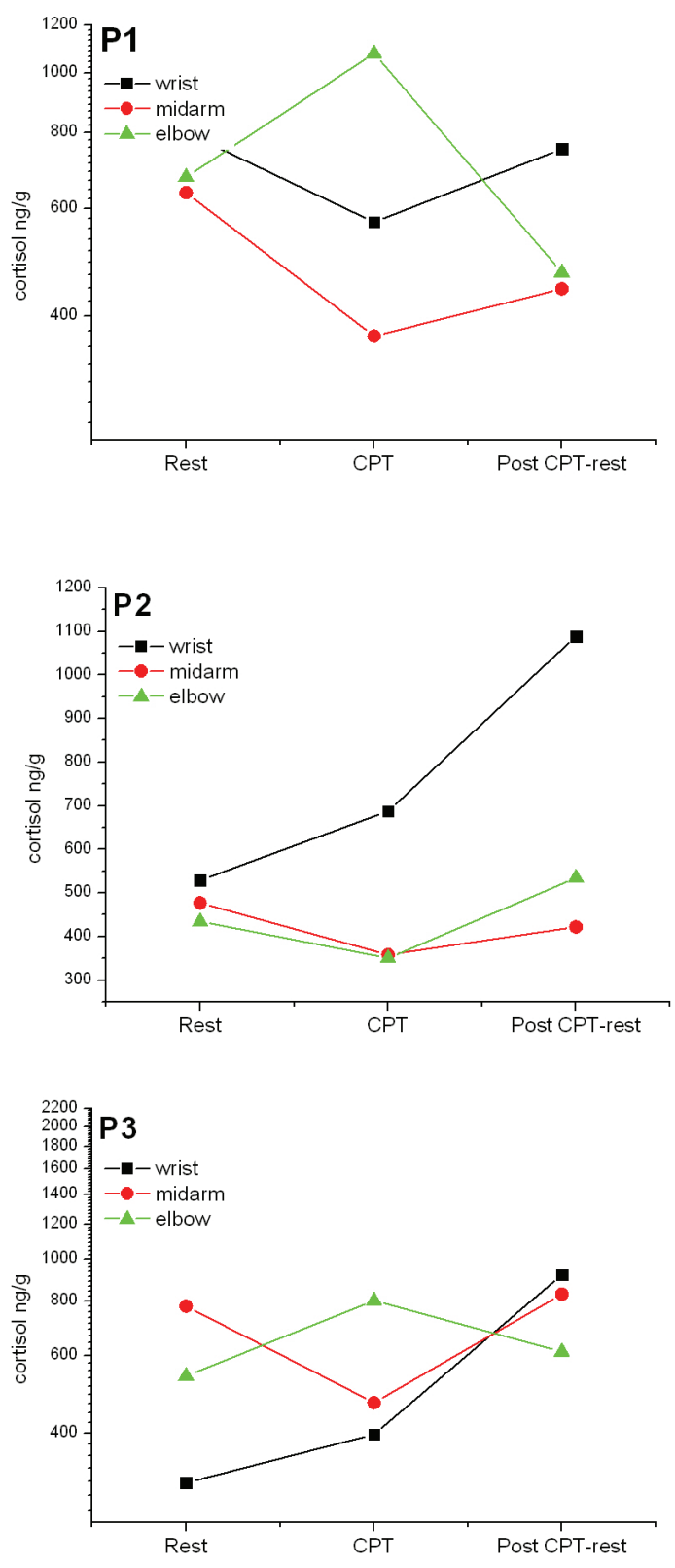

greeting and signing of appropriate consent forms, each participant sat quietly and read a recent issue of $\mathrm{New}$ Scientist for $10 \mathrm{~min}$. After this period, the first hair samples were taken from sites $a, b$, and $c$ by the first two authors acting in concert and the razors and hair were stored in their envelopes. These samples were labeled "Rest". The participant was then asked to insert his hand in ice water $\left(1{ }^{\circ} \mathrm{C}\right.$ to $4{ }^{\circ} \mathrm{C}$ ) for $1.0 \mathrm{~min}$ so that the entire hand was immersed to the head of the ulna but short of the first hair sample area. Immediately after withdrawing his hand and having it quickly dried, the second set of samples (sub-areas $d, e, f$ ) was collected ("CPT") and stored and the participant was asked to resume reading. After nine min of reading, a further sample was collected from each site $(g, h, i)$ ("Post-CPT-Rest") and stored.
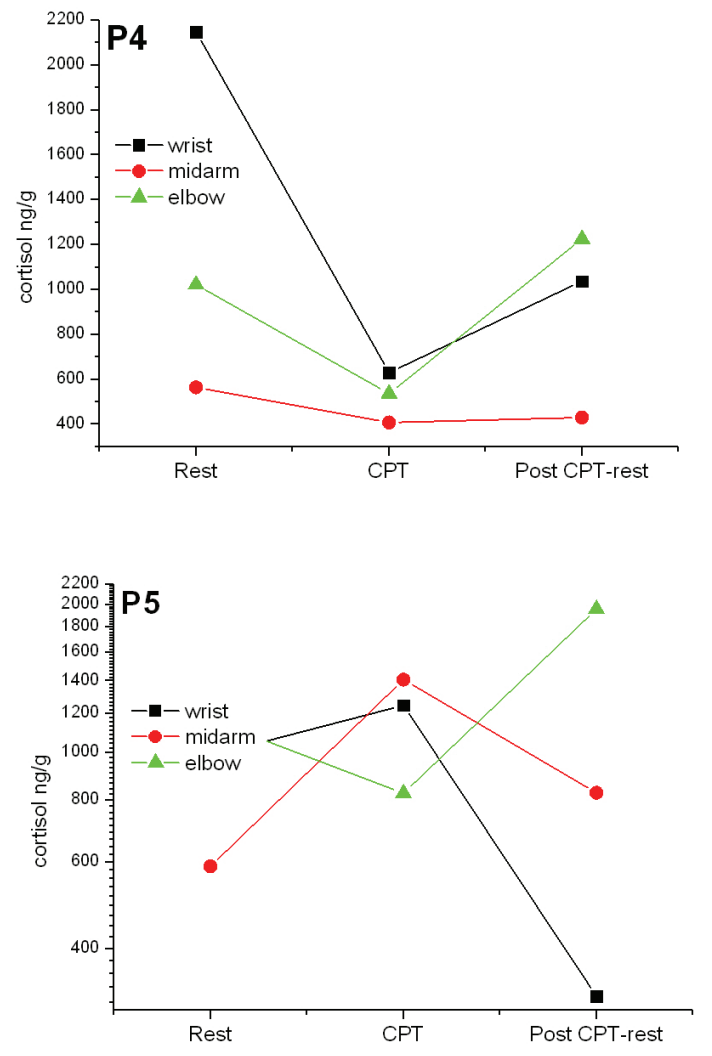

Fig. 1. Hair cortisol concentrations across three sites prior to and following CPT of participants' hands.

Participants were then thanked and given AUD\$10.00 for taking part in the experiment. All procedures were approved by the University of New England Human Experimentation Ethics Committee.

\section{Results}

Figure 1 shows each of the five participants' cortisol data from the three sites at each of the three sampling periods. Several findings emerge from these graphical presentations of the hair cortisol data. First, each participant showed variability in hair cortisol concentrations across the three sites after $10 \mathrm{~min}$ of silent reading (Rest), again after CPT and also after Post-CPTRest. Second, variability in terms of hair cortisol 
concentrations was present between participants. Third, four of the five participants (P: 1, 2, 3, 5) showed immediate increases in hair cortisol from Rest to CPT on at least one of the three sites sampled (wrist, mid-arm, elbow), with two (P: 3, 5) showing increases at two sites. Furthermore, at the Post-CPT-Rest sampling, all five participants showed increases in hair cortisol on at least one site, two sites $(\mathrm{P}: 1,3)$ or all three sites $(\mathrm{P}: 2,4)$.

\section{Discussion}

The variability in hair cortisol collected from the same sites between participants may be expected, since cortisol concentrations (like other glucocorticoids) reflect individual responsiveness to external stimuli. Variability in hair cortisol concentrations within participants and between sites was found for all participants on all three experimental data collection periods (after rest, immediately following CPT and after nine further minutes of rest), suggesting that the synthesis of cortisol in specific hair sites may be relatively independent from that in other sites.

While previous data showed that the peripheral cortisol production (in hair) was independent of the central HPA cortisol production (in saliva) and also that the stressed forearm showed different hair cortisol responses to hair cortisol from the opposite and unstressed lower leg, the present data suggest that even quite close hair cortisol production sites (i.e. within $250 \mathrm{~mm}$ of each other) may act independently of each other in the absence and presence of stressors. This "localization" effect may be more finely apparent than shown here, and further data need to be collected to test the limits of this phenomenon within closer distances than those measured in this study.

Following from the variability shown across sites and between participants, the pattern of responses to CPT was consistent with that which might be expected from an ideographically-based glucocorticoid system. That is, while four of the five participants showed immediate increases in cortisol concentrations in hair from at least one of the nearby sites (i.e. wrist, mid-arm, elbow) and all five participants showed elevations in hair cortisol by nine minutes after the end of the CPT immersion, there was an indication of some variability across participants' hair cortisol concentrations from the three sampling sites during each of the three data collection periods, as well as in the number of sites which showed cortisol elevations. These data may provide support the hypothesis of individual differences in hair cortisol responses suggested from the data discussed above, plus the finding that CPT produces uniform (across participants) hair cortisol elevations within a reasonable time (10 $\mathrm{min}$ ) after the stressor onset.

In our previous paper, we collected data at more frequent intervals (every $5 \mathrm{~min}$ for $30 \mathrm{~min}$ ) in order to compare forearm with opposite leg hair cortisol responses and salivary cortisol, but the sites of hair collection were much larger than those used herein because eight samples needed to be collected rather than three, necessitating a larger area to be shaved. In fact, in order to collect sufficient hair for eight assays of hair cortisol and compare them with data from the opposite leg, the arm sampling area in that study spread over the whole of the three sampling areas used in this study, and therefore the variability noted between the wrist, mid-arm and elbow sites in this study may have been overlooked in previous research.

These data provide some support for previous data on the responsivity of hair cortisol concentrations to relatively brief pain stressors and suggest that this glucocorticoid activity may be relatively locally-oriented. While further investigations may enable the localization boundaries to be reduced, these data suggest that areas of $250 \mathrm{~mm}$ may represent separate response sites which may have related activity to a pain stressor. CPT (and other pain) may have different effects upon different sections of the forearm across individuals so that the variability shown here may reflect an overall consistent, but locally variable, response to a site-specific stressor, and this is currently being investigated.

\section{Conflict of Interest}

There is no conflict of interest.

\section{References}

ARCK PC, SLOMINSKI A, THEOHARIDES TC, PETERS EMJ, PAUS R: Neuroimmunology of stress: skin takes center stage. J Invest Dermatol 126: 1697-1704, 2006. 
ARON DC, FINDLING JW, TYRRELL JB: Glucocorticoids and adrenal androgens. In: Basic and Clinical Endocrinology. FS GREENSPAN, D GARDNER (eds), G Lange Medical Books/McGraw-Hill, New York, 2007, pp 346-395.

CIRIMELE V, KINYZ P, DUMESTRE V, GOULLE JP, LUDES B: Identification of tem corticosteroids in human hair by liquid chromatography-ion spray mass spectrometry. Forensic Sci Int 107: 381-388, 2000.

DAVENPORT MD, TIEFENBACHER S, LUTZ CK, NOVAK MA, MEYER JS: Analysis of endogenous cortisol concentrations in the hair of Rhesus macaques. Gen Comp Endocrinol 147: 255-261, 2006.

DICKERSON SS, KEMENY ME: Acute stressors and cortisol responses: A theoretical integration and synthesis of laboratory research. Psychol Bull 130: 355-391, 2004.

GUYTON AC, HALL JE: Textbook of Medical Physiology. Elsevier, Philadelphia, PA, 2006.

HARKEY MR: Anatomy and physiology of hair. Forensic Sci Inter 63: 9-18, 1993.

ITO N, ITO T, KROMMINGA A, BETTERMAN A, TAKIGAWA M, KEESD F, STRAUB RH, PAUS R: Human hair follicles display a functional equivalent of the hypothalamic-pituitary-adrenal axis and synthesize cortisol. FASEB J 19: 1332-1334, 2005.

KALRA S, KLEIN J, KARASKOV T, WOODLAND C, EINARSON A, KOREN G: Use of hair cortisol as a biomarker of chronic stress in pregnancy. Clin Pharmacol Ther 77 (Suppl S): P69, 2005.

KLAITMAN V, ALMOG Y: Corticosteroids in sepsis: A new concept for an old drug. Isr Med Assoc J 5: 51-55, 2003.

KLEIN J, KARASKOV T, STEVENS B, YAMADA J, KOREN G: Hair cortisol - a potential biological marker for chronic stress. Clin Pharmacol Ther 75 (Suppl S): P44, 2004.

KOREN L, MOKADY O, KARASKOV T, KLEIN J, KOREN G, GEFFEN E: A novel method using hair for determining hormonal levels in wildlife. Animal Behav 63: 403-406, 2002.

PAUS R, THEOHARIDES TC, ARCK P: Neuroimmunoendocrine circuitry of the 'brain-skin connection'. Trends Immunol 27: 32-39, 2006.

RAUL JS, CIRIMELE V, LUDES B, KINTZ P: Detection of physiological concentrations of cortisol and cortisone in human hair. Clin Biochem 37: 1105-1111, 2004.

SAUVE B, KOREN G, WALSH G, TOKMAKEJIAN S, VAN UUM SH: Measurement of cortisol in human hair as a biomarker of systemic exposure. Clin Invest Med 30: E183-E191, 2007.

SHARPLEY CF, MCLEAN S: Use of salivary cortisol as an indicator of biobehavioural reactivity to a brief psychological task. Scand J Behav Ther 21: 35-45, 1992.

SHARPLEY CF, KAUTER KG, MCFARLANE JR: An initial exploration of in vivo hair cortisol responses to a brief pain stressor: latency, localization and independence effects. Physiol Res 58: 757-761, 2009.

SLOMINSKI A, ZBYTEK B, SZCZESNIEWSKI A, SEMAK I, KAMINSKI J, SWEATMAN T, WORTSMAN J: CRH stimulation of corticosteroids production in melanocytes is mediated by ACTH. Am J Physiol 288: E701E706, 2005.

UMEDA T, HIRAMATSU R, IWAOKA T, SHIMADA T, MIURA F, SATO T: Use of saliva for monitoring unbound free cortisol levels in serum. Clin Chim Acta 110: 245-253, 1981.

VAN UUM SH, SAUVÉ B, FRASER LA, MORLEY-FORSTER P, PAUL TL, KOREN G: Elevated content of cortisol in hair of patients with severe chronic pain: a novel biomarker for stress. Stress 11: 483-488, 2008.

WEISSMANN G, THOMAS L: Studies on lysosomes: II. The effect of cortisone on the release of acid hydrolases from a large granular fraction of rabbit liver induced by an excess of vitamin A. J Clin Invest 42: 661-669, 1963.

WHEELER MJ, ZHONG Y-B, KICMAN AT, COUTTS SB: The measurement of testerone in hair. J Endocrinol 159: R5-R8, 1998.

YAMADA J, STEVENS B, DE SILVA N, GIBBINS S, BEYENE J, TADDIO A, NEWMAN C, KOREN G: Hair cortisol as a potential biologic marker of chronic stress in hospitalized neonates. Neonatology 92: 42-49, 2007.

YANG HZ, LAN J, MENG YJ, WAN XJ, HAN DW: A preliminary study of steroid reproductive hormones in human hair. J Steroid Biochem Mol Biol 67: 447-450, 1998.

YUEN BS, OWENS PC, SYMONDS ME, KEISLER DH, MCFARLANE JR, KAUTER KG, MCMILLEN IC: Effects of leptin on fetal plasma adrenocorticotropic hormone and cortisol concentrations and the timing of parturition in the sheep. Biol Reprod 70: 1650-1657, 2004. 